\title{
CFD SIMULATION OF OBSTRUCTED VENTILATION PORTS IN A SUBWAY TUNNEL SECTION
}

\author{
Flores-Herrera, L. A.; Sandoval-Pineda, J. M.; Silva-Rivera, U. S.; Tamayo-Meza, P. A. \& \\ Rivera-Blas, R. \\ Instituto Politécnico Nacional, Esc. Sup. Ing. Mec. y Elec., Sec. Est. Posg. Inv., U. A., \\ Av. Granjas No. 682, Col. Sta. Catarina, Azcapotzalco, C.P. 02250, Ciudad de México, Mexico \\ E-Mail: lafloresh@ipn.mx.com, usilva@ convergenteng.com
}

\begin{abstract}
A CFD simulation of the air velocity in a subway tunnel section of $1400 \mathrm{~m}$ in length is presented. In this case of study; the simulation compares the air velocity changes when two of six natural ventilation ports are totally obstructed. They are required for hot air exhaust, smoke release and fresh air intake. The mechanical ventilation system is located inside the tunnel at $650 \mathrm{~m}$ from the end of a passenger platform and $750 \mathrm{~m}$ from the other, it is a non-symmetrical scenario. The simulation was carried in ANSYS ${ }^{\circledR}$ Fluent compared with NFPA calculation and considering geometries and dimensions of an actual subway section of the Mexico City. Four different numerical models were created to analyse eight different cases. The results indicate that the obstruction of the ports create a non-homogeneous distribution of the flow velocity inside the passenger platform with an approximate difference of 1.5 $\mathrm{m} / \mathrm{s}$. This value is very important in cases when the backlayering effect has to be avoided as in the case of smoke transportation, exhaust of smoke and the transport of dust or some other contaminant. The emergency procedures and the design of escape routes can be improved by considering the physical changes occurring when the ventilation ports are obstructed. Since the atmospheric pressure influence the direction and velocity of the flow coming from the non-obstructed vents.

(Received in September 2016, accepted in February 2017. This paper was with the authors 1 month for 2 revisions.)
\end{abstract}

Key Words: Obstructed Ports, Fan Deflector, Critical Velocity, Subway, CFD

\section{INTRODUCTION}

Modern cities require Intelligent Transportation Systems that comply with the safety conditions, comfort and a suitable infrastructure. The subway system is one of them, since its operation must ensure the demanding transportation needs of big cities that are constantly growing and changing [1]. The origin of this study comes out from a particular situation in which two ventilation ports are accidentally or intentionally obstructed with cardboard and trash. This is because the noise coming from the subway can reach up to $85 \mathrm{~dB}$. Therefore this situation compromises the safety inside the tunnel and the passenger platform especially in the case of a possible fire because the altered characteristics of the ventilation flow. In addition, construction of underground facilities is strongly related to the implementation of complex safety systems, because these facilities may be exposed to different emergency scenarios such as, floods, earthquakes, explosions, leaks of toxic gas, power failures and others. Among them, the most threatening danger for people is fire, as it represents approximately $57 \%$ of all of the mentioned disasters [2]. Appropriate ducts for natural and mechanical ventilation systems are required during the construction and operation of tunnels, passenger platforms and other underground facilities required for auxiliary subway services. They are also intended to provide enough air conditions for the passengers under normal operating conditions and in the case of fire emergencies; to provide suitable evacuation of smoke not only for the temperature and contamination effects but also because it creates reduced visibility increasing the panic of the passengers $[3,4]$.

The behaviour of fire and enclosed hot air in underground facilities is subjected to the influence of internal and external environmental conditions [5, 6], but also to several 
interactions between the products of combustion, like buoyancy and momentum among others [7, 8]. Empirical, experimental and numerical models have been used to observe the flow behaviour and the effect of critical velocity, smoke and temperature distribution, they are used to establish the relation between air velocity and heat release rates [9-12].

The characteristics of the ventilation systems can be determined by considering the procedures provided by the National Fire Protection Association (NFPA 130-7) [13]. The procedures include the calculation of the critical velocity required to prevent the backlayering phenomenon during the emission of smoke [14-16].

Architectural details of the subway tunnels and platforms play also an important role during the performance of a ventilation system. In the case of fire, the transportation of smoke along the tunnel is altered by its slope, length, traffic, etc., and the obstruction of the ventilation ports increase a different variable in the analysis of physical scenario apart from external weather conditions [17-25]. The complexity of the situation creates the need not only for the creation of general but for particular emergency response procedures [26].

In this study, a ventilation system for an actual subway tunnel was analysed, considering a special study case in which two natural ventilation ports are blocked which is a recurring situation in some subways in Mexico City. Here the sections of tunnels usually have two ventilation ports in each passenger platform, that are independent of the access corridors for the people and on the tunnel they have at least another two natural ventilation ports depending of the tunnel length. Also the problem is that ventilation ports are often obstructed by people who throw garbage to reduce noise. Thus the aim of this paper is to analyse the effects in the wind flow when two ports are totally blocked, as well as to determine if with a deflector in the mechanical ventilation port, the ventilation conditions will be maintained even with the obstructed ports.

\section{MATERIALS AND METHODS}

\subsection{Numerical models}

Initially, the critical velocity that must be maintained inside a tunnel of the same length is determined according to the NFPA 130-7. In several mechanical ventilation systems, an operator can determine whether to use the fans in the injection or extraction modes according to ventilation needs. But in case of fire, various elements such as the location and characteristics of the fire source must be considered first in order to determine the operation mode of the fans; this is far beyond the presented analysis.

This study focuses only on the observation of flow changes due the obstruction of the ventilation ports. For this purpose, four different numerical models were constructed:

- The first one is a straight tunnel of $1100 \mathrm{~m}$ in length used to compare the resulting air velocity with the one obtained with the NFPA calculation; cases 1 and 2.

- The second model includes two platforms on each side, and six ventilation ports. This tunnel considers real dimensions found in a Mexico City subway facility. Figure 1 a, shows one segment of the actual tunnel, with two natural ventilation ports located before the passenger platforms, such as the case of the Ventilation Port 3 (VP 3) observed in Fig. 1 b, that is similar in dimensions to the Ventilation Port 4 (VP 4). These regions are important because the volume of air flowing through the tunnel suffers an instantaneous cross section changes, it was used for cases 3 and 4.

- The third model is a copy of the second but with VP 3 and VP 4 totally obstructed, it was considered for cases 5 and 6 .

- The fourth and last model for cases 7 and 8 , is a modification of the third model but includes an air deflector, here VP 3 and VP 4 are blocked again. 
Since the fans are oriented perpendicular to the tunnel, the inclusion of the deflector was considered to increase the velocity in the tunnel without modification of the fans. Figs. 1c and $1 \mathrm{~d}$, show the fan facility from inside the tunnel. Fig. 2 shows the isometric view of the third model, which can be representative also for cases 3 to 8 .

All the models were analysed in both cases; injection and extraction modes at $10 \mathrm{~m} / \mathrm{s}$ and with the same physical parameters. In addition a comparison of the velocity vectors was carried out in the passenger platform number 2 (the farthest), for each of the eight cases analysed because the corresponding VP 4 creates an interesting effect on the air velocity inside the platform.

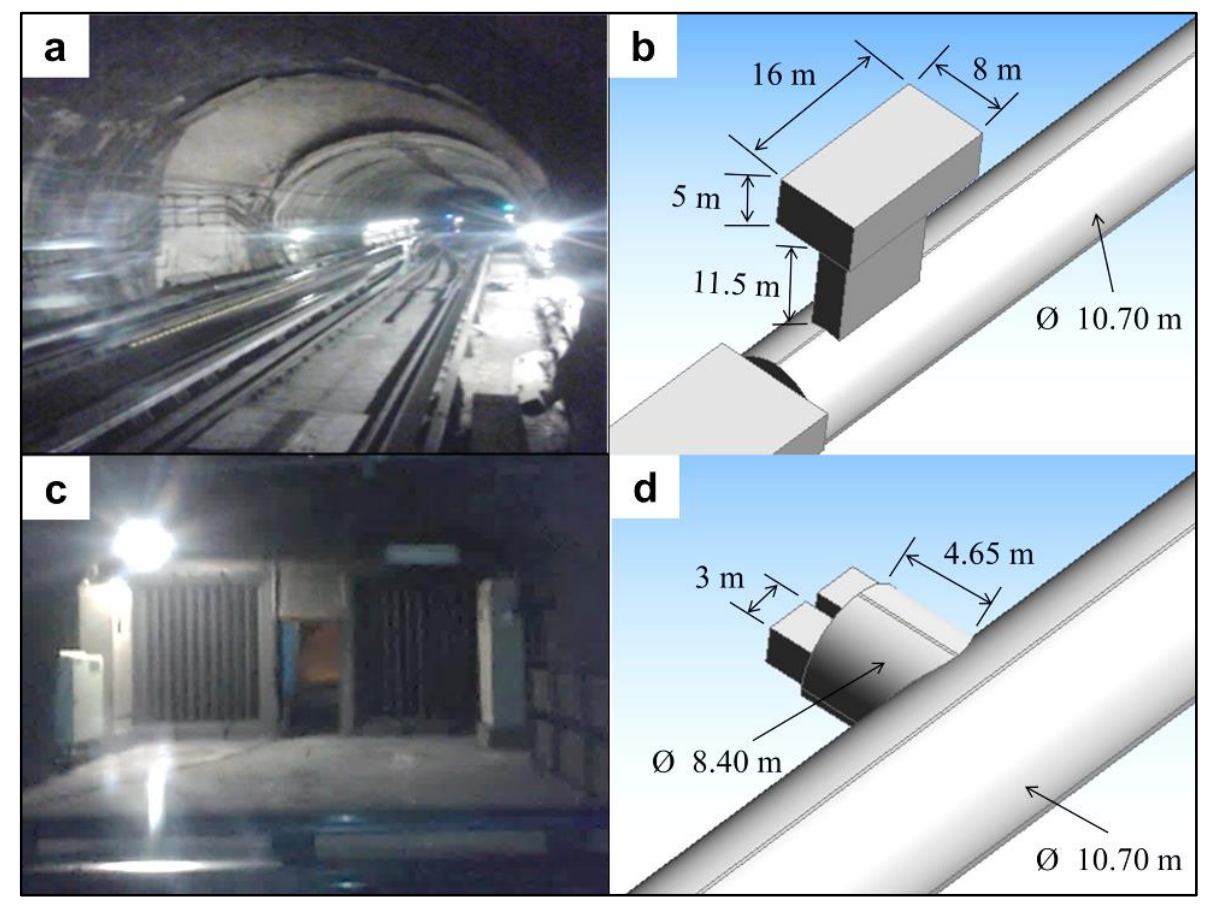

Figure 1: a) Actual view of the tunnel, b) dimensions of the natural ventilation port VP 3, c) exhaust facility of the mechanical ventilation port and d) dimensions of this mechanical ventilation port composed by two fans.

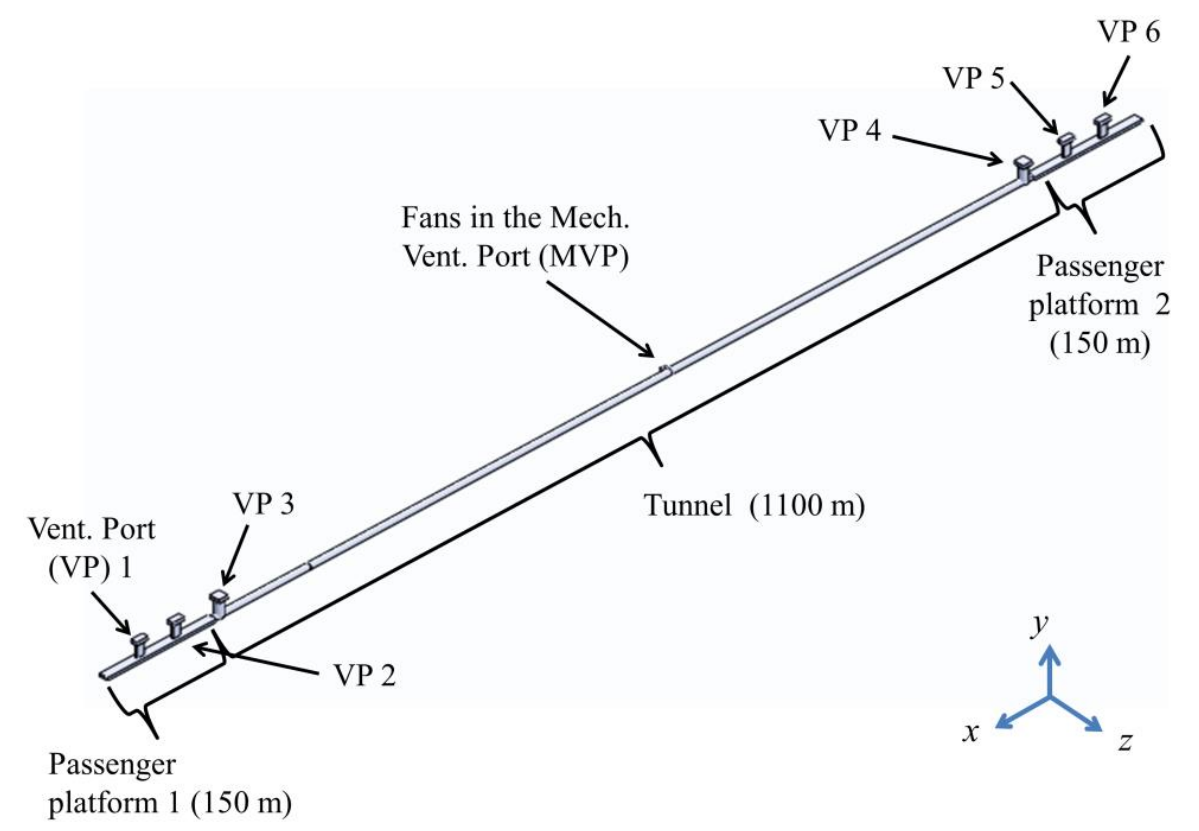

Figure 2: Isometric view of the third model. 


\subsection{Boundary regions for each model}

Fig. 3 shows the characteristics of models constructed for the eight cases. It is important to notice that the fan facility is composed by two fans installed in the same room, that are perpendicularly oriented respect to the tunnel as shown in Figs. $3 \mathrm{~d}$ and $3 \mathrm{e}$.
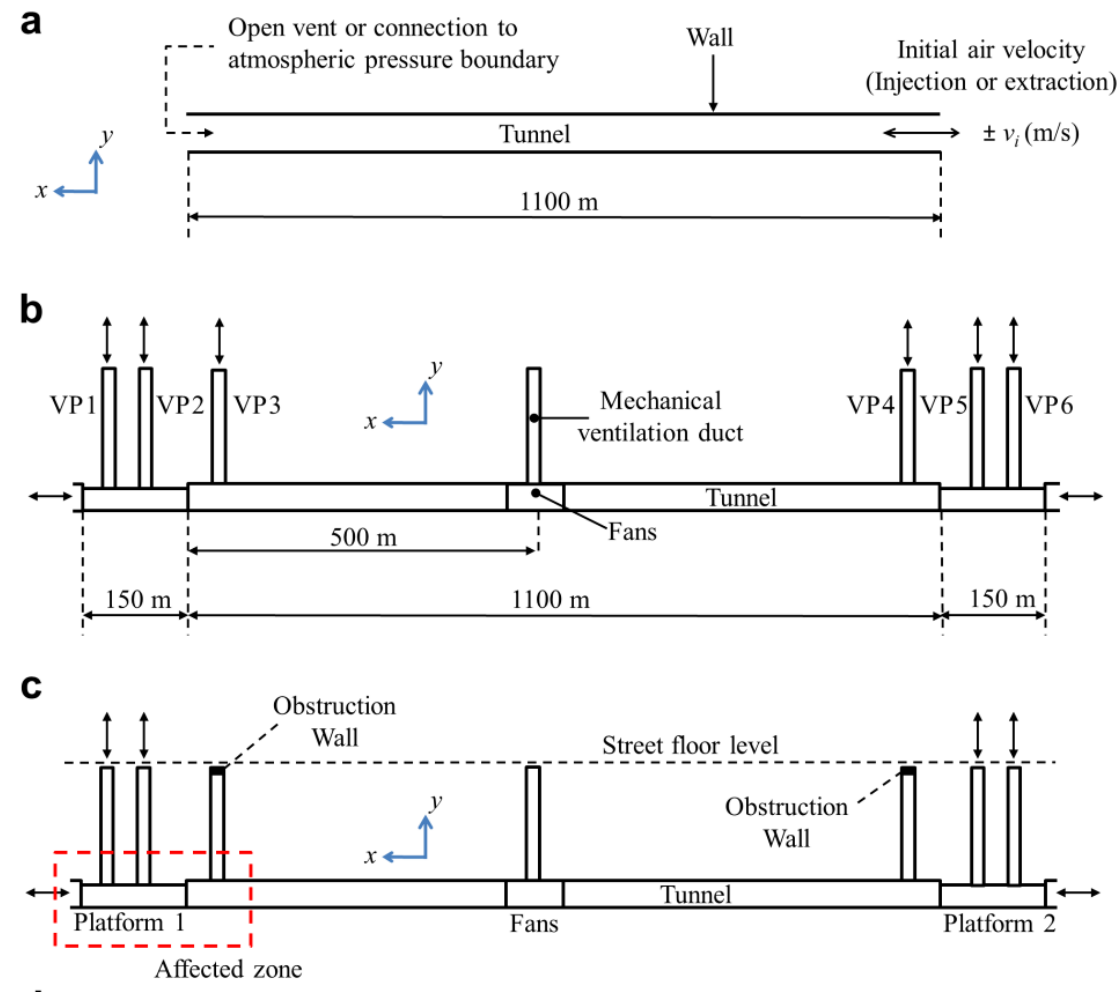

d

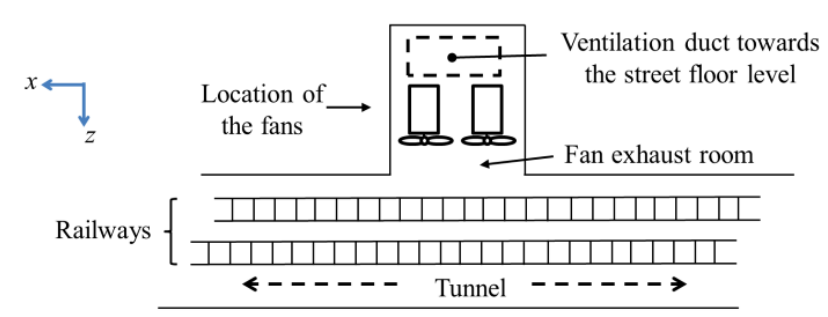

e

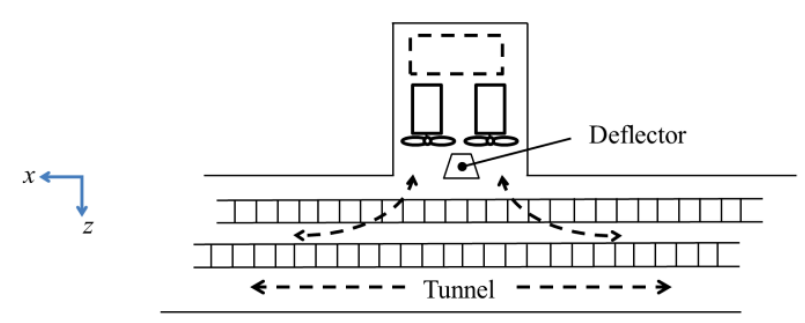

Figure 3: Characteristics of the models and boundary regions: a) Lateral view of the $1^{\text {st }}$ model for cases 1 and 2, b) Lateral view of the $2^{\text {nd }}$ model for cases 3 and $4, c$ ) Lateral view of the $3^{\text {rd }}$ model for cases 5 and 6 , d) Top view of the fans room, e) Top view of the modification on the $4^{\text {th }}$ model for cases $7-8$.

\subsection{Pre-processing}

The creation of the CAD models was carried out in the ANSYS ${ }^{\circledR}$ Geometry module, following a series of sketches and extrusions. The advantage of working directly in the CAD platform of the software is that the number of errors related to mesh generation are reduced or avoided. During the export-import procedures of CAD models, when they are created in a 
non-native analysis software, there exist the possibility of the automatic generation of small extra geometries. They used to appear especially in complex shapes or sharp geometric joints as well as in small chamfered cross section changes. These small geometric modifications some times are not easy to find. The resulting numerical model containing this extra elements or the lack of them do not contribute properly to the calculation and can create warnings or meshing errors.

The physical values considered for the calculation are listed in Table I, these values were included during the pre-processing step.

Table I: Numerical values considered for the calculation.

\begin{tabular}{|l|c|}
\hline \multicolumn{1}{|c|}{ Physical parameters } & Value \\
\hline Density & $1.225 \mathrm{~kg} / \mathrm{m}^{3}$ \\
\hline Reference temperature & $298.15^{\circ} \mathrm{K}$ \\
\hline Viscosity & $1.7894 \times 10^{-5} \mathrm{~kg} / \mathrm{m} \cdot \mathrm{s}$ \\
\hline Froude number & 0.606 \\
\hline Acceleration of gravity & $9.81 \mathrm{~m} / \mathrm{s}^{2}$ \\
\hline Buoyancy & On \\
\hline Height of the tunnel & $3.85 \mathrm{~m}$ \\
\hline Slope of the tunnel & $3 \%$ \\
\hline Air density (average) & $1.2 \mathrm{~kg} / \mathrm{m}^{3}$ \\
\hline Specific heat (air) & $47.61 \mathrm{~m}^{2}$ \\
\hline Cross section area & $298.15^{\circ} \mathrm{K}$ \\
\hline Temperature of fresh air & $101325 \mathrm{~Pa}$ \\
\hline Gauge Pressure & $7.5 \mathrm{~m}^{2}$ \\
\hline Cross fan section area (each one) & $1400 \mathrm{~m}$ \\
\hline Total length & 0.80 \\
\hline Turbulent kinetic energy (second order upwind) & 0.80 \\
\hline Turbulent dissipation rate (second order upwind) & \\
\hline
\end{tabular}

\subsection{VOF meshing}

The resulting mesh size for each numerical model is shown in Table II as well as the qualification level achieved. This final tetrahedral element mesh was the result of several nodal analysis and trials as well as meshing adjustments until a suitable equilibrium was achieved for each numerical model. This mesh was considered to create the control volume required in the VOF method.

Table II: Meshing conditions of each model.

\begin{tabular}{|l|c|c|c|c|}
\hline \multicolumn{1}{|c|}{ Description } & Model 1 & Model 2 & Model 3 & Model 4 \\
\hline Nodes & 1047800 & 705579 & 705579 & 704649 \\
\hline Elements & 878670 & 3535934 & 3535934 & 3530537 \\
\hline Orthogonal quality & 0.9341 & 0.8487 & 0.8487 & 0.8485 \\
\hline Skewness & 0.2688 & 0.2459 & 0.2459 & 0.2461 \\
\hline Element quality & 0.5488 & 0.8245 & 0.8245 & 0.8244 \\
\hline
\end{tabular}

A large number of nodes require enormous computer capacity which is not necessary for this case. Consider a cross section view of the tunnel of high $h$ and width $w$; for an identical distribution of nodes $S_{n}$ along the external curve $S$ as in Fig. 4 a, the distance between nodes with respect to an idealized central node is given by Eq. (1):

$$
r_{a}<r_{b}<r_{c}
$$

where $r_{a}, r_{b}$ and $r_{c}$ are the nodal distances inside the control volume with respect to some idealized central node. There is the possibility that only one node located in this centre creates 
a unique joint between the external lines of the elements. To avoid that, the interpolation will have better convergence in a nodal distribution similar to the one shown in Fig. 4 b for the first model.

a

b
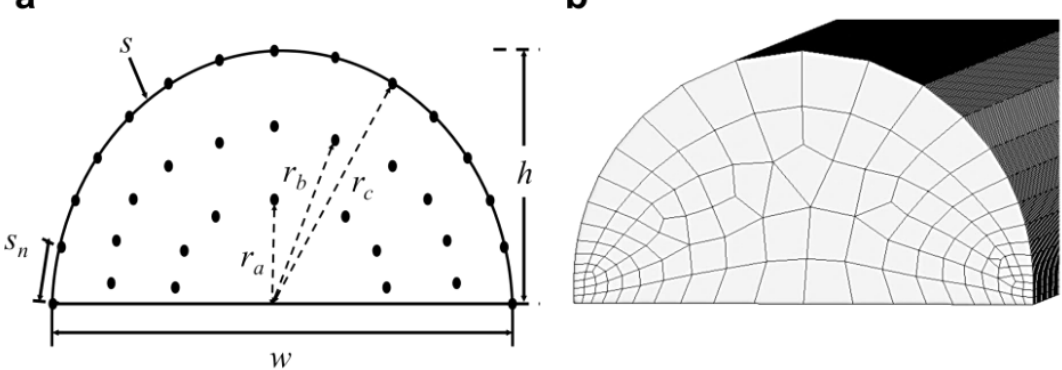

Figure 4: Nodal distribution inside the volume of control.

An increased amount of nodes were located only in the transition zones, and especially in the geometrical cross section changes as well as in the intersection between the fans facility and the tunnel. The geometrical connection of the tunnel with the passenger platform and also with the vent ports represents sudden geometrical changes also in which the generation of continuous vortex is expected.

The top view of the final discretization for second and third models is shown in Fig. 5 a, and the fourth model is represented in Fig. 5 b. These models are compared just on the fans location and their connection with the tunnel. The inclusion of the deflector required the generation of new mesh trials to achieve good qualification.

The original orientation of the fans creates a velocity loss due the direct impact with the boundary wall. In just a few meters towards the tunnel, the velocity dropped as it is observed in the results. The deflector creates a new theoretical boundary layer that reduces the cross section of the flow with a sudden increment on the velocity and pressure drop.

a
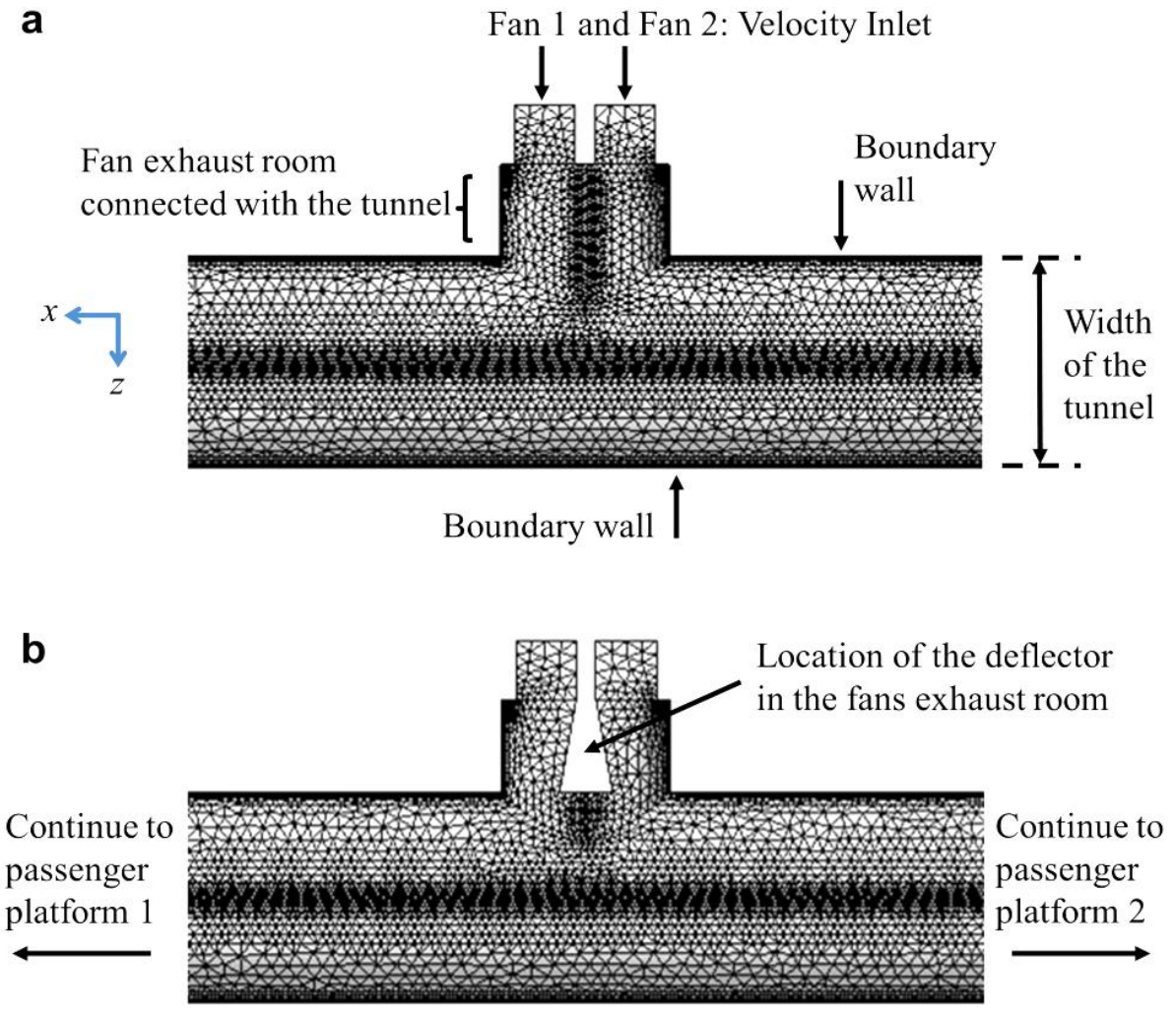

Figure 5: a) Top view of the fans facility perpendicular to the direction of the tunnel and b) inclusion of the deflector for the fourth numerical model. 


\subsection{Solver criteria}

The Pressure Based Solver method with the coupled option was used as the solution criteria, it works in a simultaneous way in ANSYS $^{\circledR}$ Fluent, as opposed to the segregated type that solves the problem sequentially. The numerical scenario considers the solution of the mass conservation of Eq. (2) and momentum equation given in Eq. (3) [27-29].

$$
\begin{gathered}
\frac{\partial}{\partial t}(\rho \overrightarrow{\mathrm{v}})+\nabla(\rho \overrightarrow{\mathrm{v}})=S_{m} \\
\frac{\partial}{\partial t}(\rho \overrightarrow{\mathrm{v}})+\nabla(\overrightarrow{\mathrm{v}} \overrightarrow{\mathrm{v}})=-\nabla P+(\overline{\bar{\tau}})+\rho \overrightarrow{\mathrm{g}}+\overrightarrow{\mathrm{F}}
\end{gathered}
$$

where $\rho$ is the density, $\overrightarrow{\mathrm{v}}$ is the velocity vector and $S_{m}$ is the mass added; in this case $S_{m}=0$. In the momentum equation; $P$ represents the pressure, $\vec{g}$ the gravitational body force and $\overrightarrow{\mathrm{F}}$ the external body force.

Within the spatial discretization, a second order scheme was selected for the Pressure interpolation and a second order upwind scheme for the Energy and the turbulent dissipation rate.

\section{OBTAINED RESULTS}

A path line crossing through the geometrical centre of the model was placed to analyse the results. The air velocity was measured along the points of this line and plotted with respect to the length. At the top side of the graphs, a simplified geometry of the tunnel was included to observe the location of the behaviour. Figs. 6 a and $6 \mathrm{~b}$ show the resulting air velocity for the validation analysis which corresponds to cases 1 and 2 . This result agrees with the NFPA calculation with a difference of $0.02 \mathrm{~m} / \mathrm{s}$ with respect to the CFD simulation.
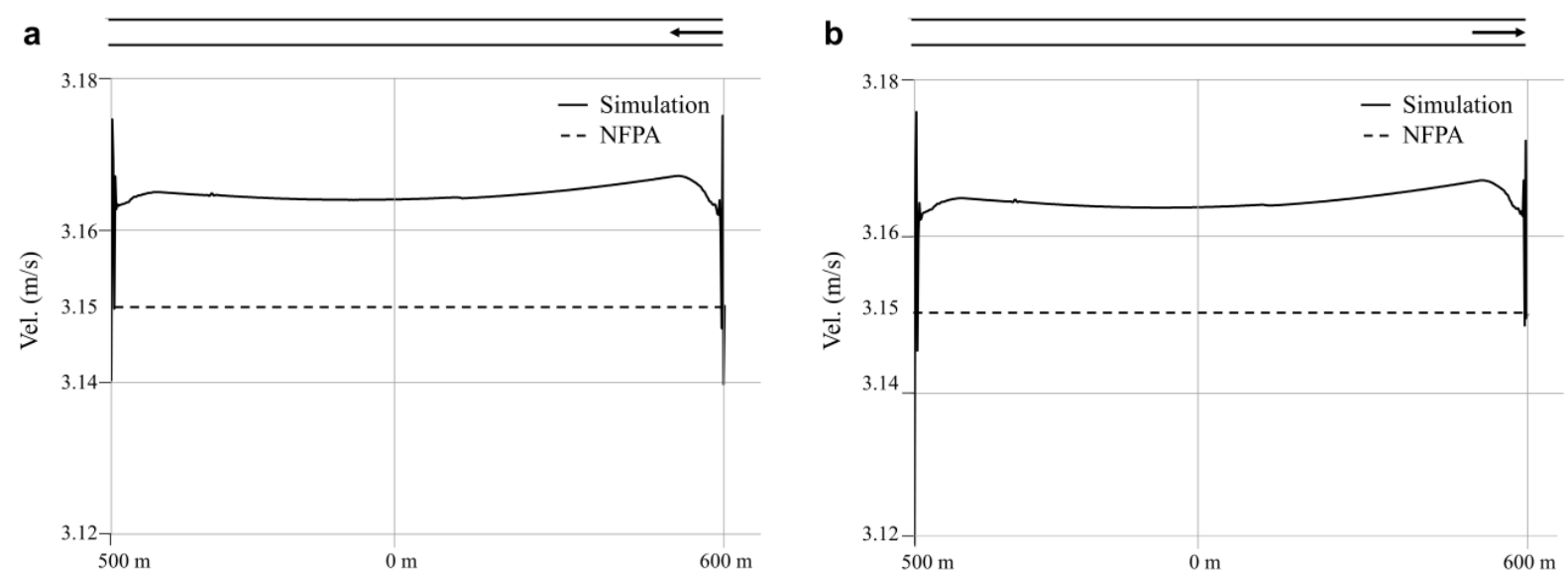

Figure 6: Horizontal air velocity for the validation analysis; a) case 1, injection mode and b) case 2, extraction mode.

Figs. $7 \mathrm{a}$ and $7 \mathrm{~b}$ correspond to cases 3 and 4 respectively. A high peak of velocity is observed close to the centre of the graph, where the fans are located. It is interesting to observe the small differences in case 3 , from $1.42 \mathrm{~m} / \mathrm{s}$ to $1.39 \mathrm{~m} / \mathrm{s}$ between the left and right sides of the tunnel. These values agree if compared with the ones obtained by Zhang [17]. In case 4 , the difference is $0.1 \mathrm{~m} / \mathrm{s}$ between both sides of the tunnel. On both cases, the velocity is greater on the shorter length side. 

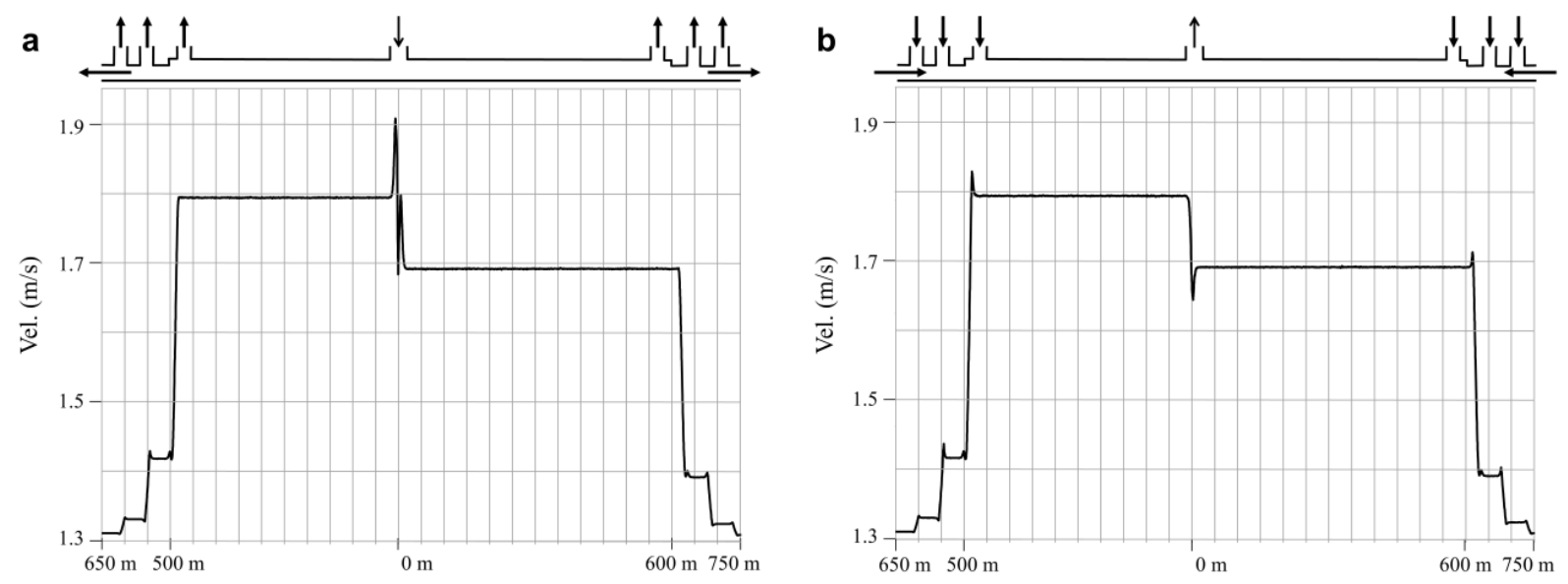

Figure 7: Horizontal velocity of the air for a) case 3, injection mode and open vents and b) case 4, extraction mode and open vents.

Cases 5 and 6 are shown in Figs. 8 a and 8 b respectively, where the natural ventilation ports VP 3 and VP 4 were totally obstructed. The air velocity has a small increment of $0.1 \mathrm{~m} / \mathrm{s}$ with respect to cases 3 and 4 . Notorious changes on the velocity of the flow are observed inside the platform. This is another interesting result: two different velocities can be achieved inside the passenger platform because of the obstruction. The emergency procedures have to consider this effect, especially in the case of smoke, dust or any other contaminants coming from the tunnel.
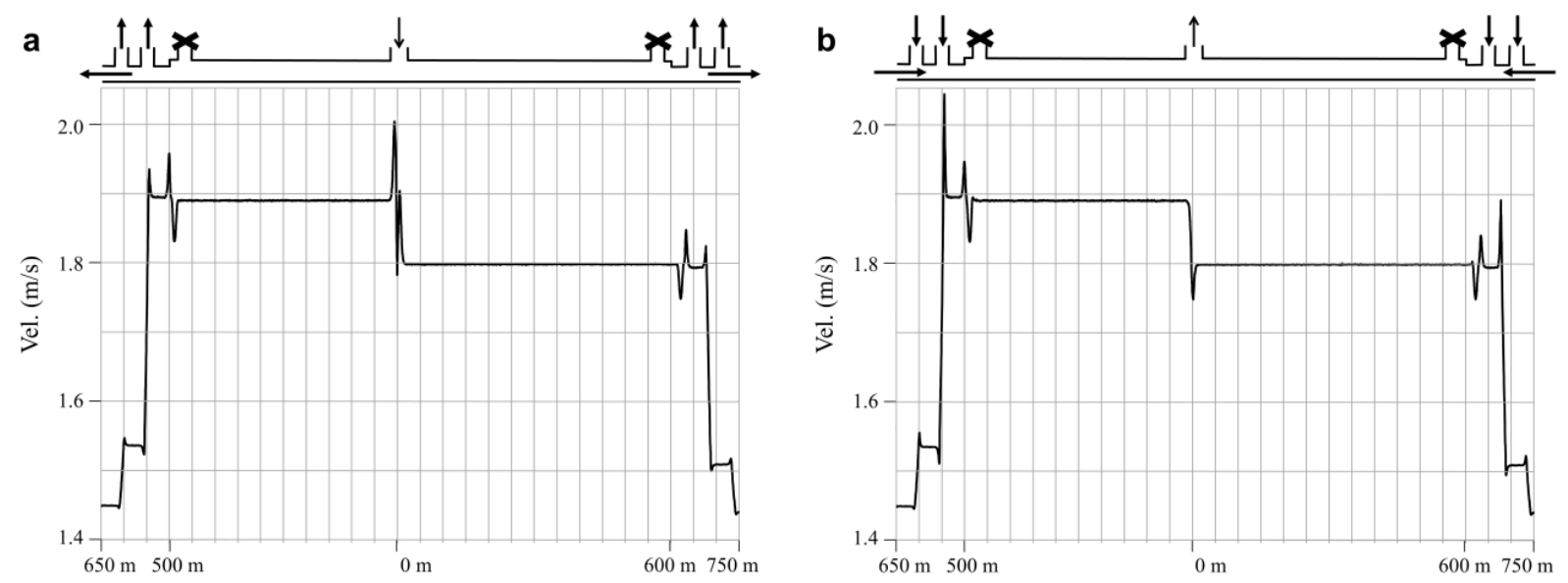

Figure 8: Horizontal velocity of the air along the tunnel for a) case 5, injection mode and obstructed vents and b) case 6 , extraction mode and obstructed vents.

Figs. $9 \mathrm{a}$ and $9 \mathrm{~b}$ correspond to cases 7 and 8 , where the deflector as a geometric variable is included. With respect to the injection mode, as expected, the velocity coming from the fans is increased up to $2.2 \mathrm{~m} / \mathrm{s}$, after that, the velocity in the tunnel falls down below $0.5 \mathrm{~m} / \mathrm{s}$. This indicates that the deflector creates pressure loss that is not enough to maintain adequate ventilation conditions.

In the extraction mode this situation is not the same, instead of that, the velocity is kept above $1.8 \mathrm{~m} / \mathrm{s}$ along the tunnel and at least $1.6 \mathrm{~m} / \mathrm{s}$ in the passenger platforms.

Cases 7 and 8 present the most interesting phenomenon of these simulations. In the injection mode, the inclusion of the deflector has a negative influence in the performance of the ventilation. In the extraction mode, the atmospheric pressure influencing VP 1, VP 2, VP 5 and VP 6 create enough energy to maintain adequate ventilation velocity even when the deflector creates a pressure loss. 

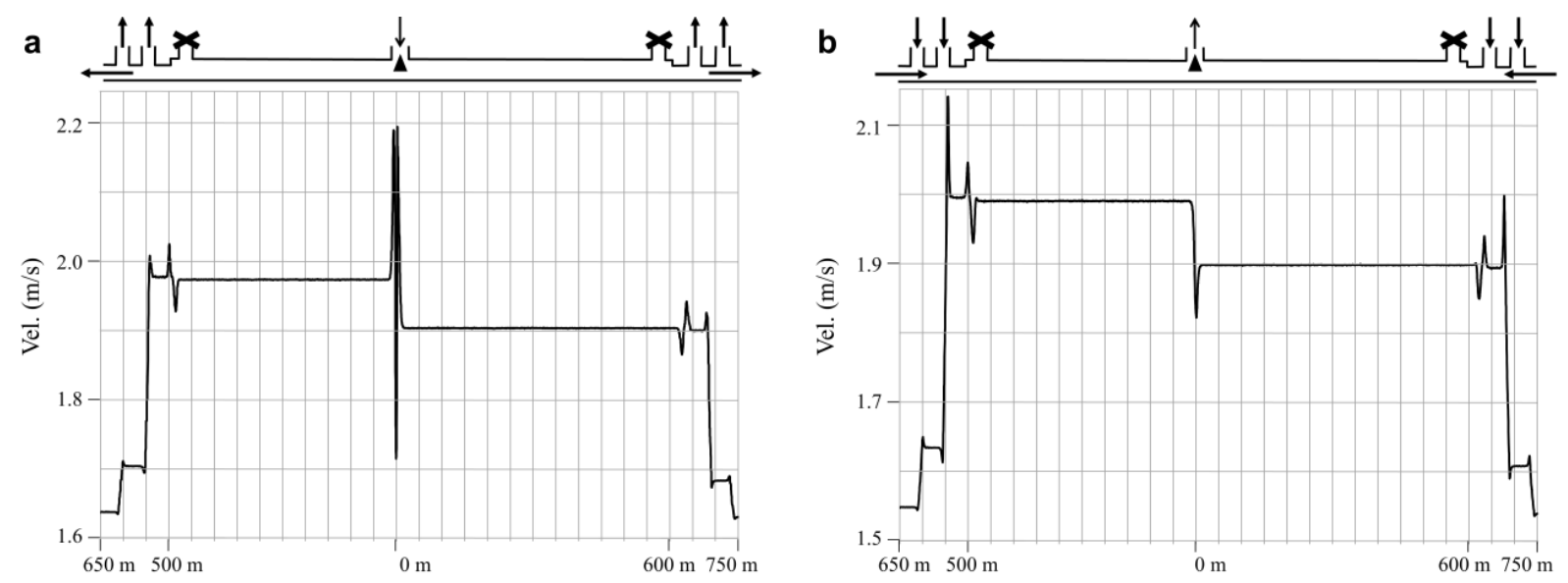

Figure 9: Horizontal velocity of the air along the tunnel with the deflector for a) case 7, injection mode and obstructed vents and b) case 8 , extraction mode and obstructed vents.

Table III presents the comparison of velocity changes between the resulting horizontal velocity provided by the fans and the corresponding maintained velocity along the tunnel.

Table III: Comparison of velocity changes.

\begin{tabular}{|c|c|c|c|c|c|}
\hline Case & $\begin{array}{c}\text { Initial velocity } \\
\text { towards the left } \\
\text { side of the } \\
\text { tunnel }(\mathrm{m} / \mathrm{s})\end{array}$ & $\begin{array}{c}\text { Resulting } \\
\text { velocity along } \\
\text { the left side of } \\
\text { the tunnel }(\mathrm{m} / \mathrm{s})\end{array}$ & $\begin{array}{c}\text { Initial velocity } \\
\text { towards the } \\
\text { right side of the } \\
\text { tunnel }(\mathrm{m} / \mathrm{s})\end{array}$ & $\begin{array}{c}\text { Resulting } \\
\text { velocity along } \\
\text { the right side of } \\
\text { the tunnel }(\mathrm{m} / \mathrm{s})\end{array}$ & $\begin{array}{c}\text { Maximum } \\
\text { difference } \\
(\mathrm{m} / \mathrm{s})\end{array}$ \\
\hline 1 & 3.175 & 3.16 & 3.175 & 3.16 & $<0.1$ \\
\hline 2 & 3.179 & 3.16 & 3.179 & 3.16 & $<0.1$ \\
\hline 3 & 1.9 & 1.8 & 1.7 & 1.7 & 0.1 \\
\hline 4 & 1.8 & 1.8 & 1.65 & 1.7 & 0.05 \\
\hline 5 & 2 & 1.9 & 1.8 & 1.8 & $<0.1$ \\
\hline 6 & 1.9 & 1.9 & 1.75 & 1.8 & $<0.1$ \\
\hline 7 & 2.2 & 1.2 & 0.1 & 0.4 & $>2.1$ \\
\hline 8 & 2.0 & 2.0 & 1.82 & 1.9 & 1.18 \\
\hline
\end{tabular}

Table IV shows a velocity comparison between the NFPA and the ANSYS ${ }^{\circledR}$ Fluent results.

Table IV: Air velocity results for each analysis case.

\begin{tabular}{|c|l|c|c|}
\hline \multirow{2}{*}{ Case } & \multicolumn{1}{|c|}{ Ventilation mode } & \multicolumn{2}{|c|}{$\begin{array}{c}\text { Air velocity along the } \\
\text { path line (m/s) }\end{array}$} \\
\cline { 3 - 4 } & & NFPA & ANSYS \\
\hline 1 & Air injection into a straight tunnel section to validate the system & 3.16 & 3.17 \\
\hline 2 & Air extraction into a straight tunnel section to validate the system & 3.16 & 3.17 \\
\hline 3 & $\begin{array}{l}\text { Air injection with actual geometry; two passenger platforms, six } \\
\text { natural ventilation ports and one mechanical ventilation port }\end{array}$ & 1.70 & 1.80 \\
\hline 4 & $\begin{array}{l}\text { Air extraction with actual geometry; two passenger platforms, six } \\
\text { natural ventilation ports and one mechanical ventilation port }\end{array}$ & 1.70 & 1.80 \\
\hline 5 & $\begin{array}{l}\text { Air injection into actual tunnel section with two totally obstructed } \\
\text { ventilation ports }\end{array}$ & 1.80 & 1.90 \\
\hline 6 & $\begin{array}{l}\text { Air extraction into actual tunnel section with two totally obstructed } \\
\text { ventilation ports }\end{array}$ & 1.80 & 1.90 \\
\hline 7 & $\begin{array}{l}\text { Air injection into actual tunnel section with deflector and two ports } \\
\text { totally obstructed }\end{array}$ & 1.90 & 1.98 \\
\hline 8 & $\begin{array}{l}\text { Air extraction into actual tunnel section with deflector and two } \\
\text { ports totally obstructed }\end{array}$ & 1.90 & 2.00 \\
\hline
\end{tabular}


A top view of the air velocity vector distribution on the fans facility for case 5 in injection mode is shown in Fig. 10 a and for extraction in Fig. 10 b (case 6), on both cases the direction of the flow suffers an instantaneous change and the pressure falls in few meters. Fig. 11 shows also the same top view but for cases 7 and 8, for injection in Fig. 11 a and for extraction in Fig. 11 b.

a

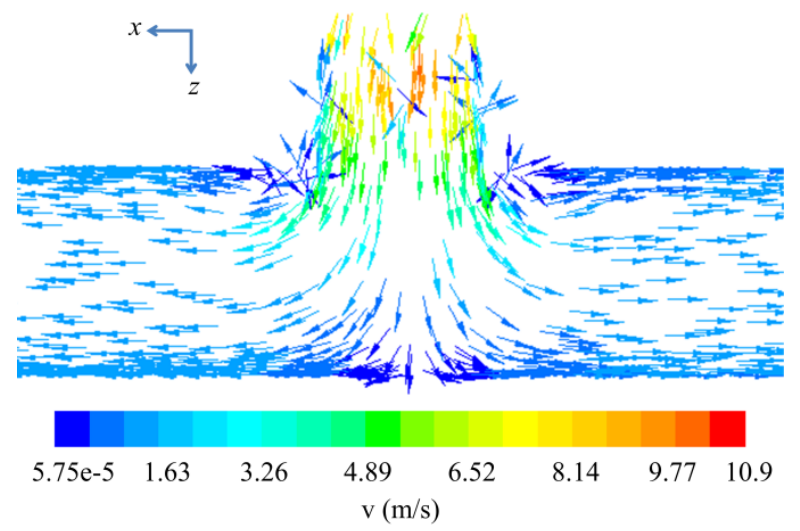

b

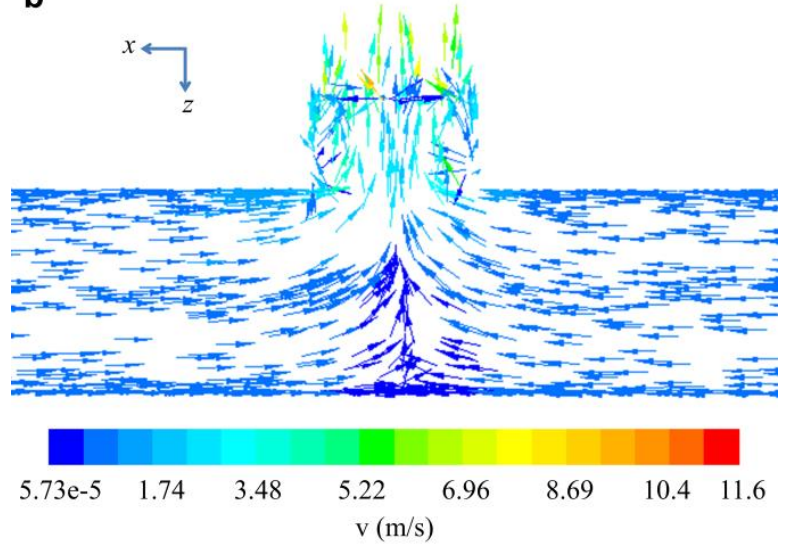

Figure 10: Top view of the air velocity vector distribution for a) case 5 and b) case 6 .

a

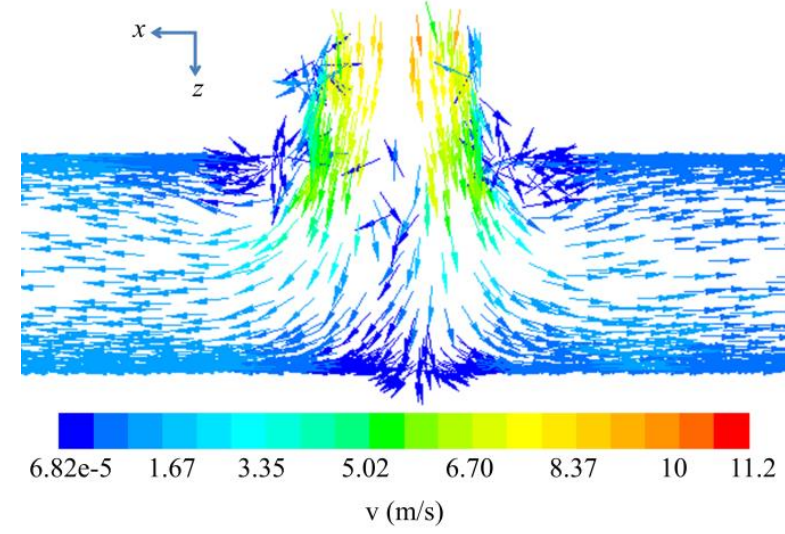

b

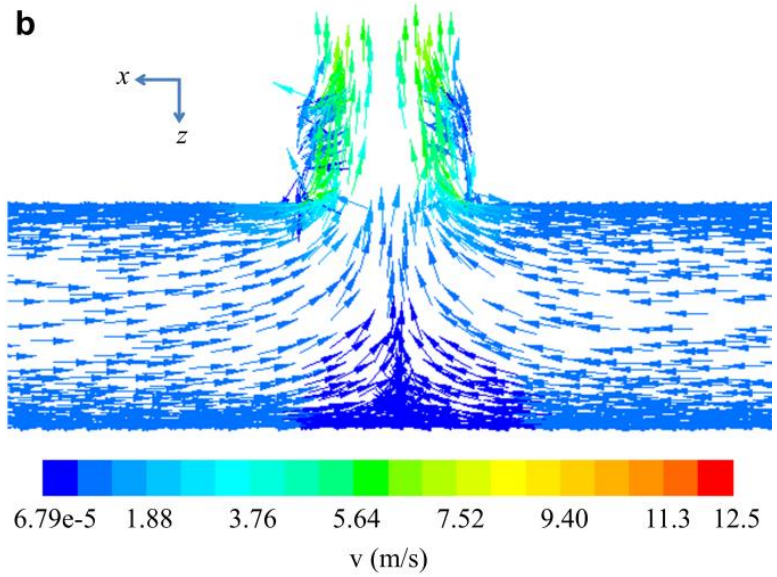

Figure 11: Top view of the air velocity vector distribution for a) case 7 and b) case 8 .

Fig. 12 a shows the path lines of the velocity distribution for case 3, it is a close view on the union between the passenger platform and the tunnel. VP 4 and VP 5 are connected to the atmosphere and the air flows from the tunnel towards the platform. VP 4 is the main channel in which the air is expelled to the atmosphere. Similarly Fig. $12 \mathrm{~b}$ shows the velocity path lines for case 5, where the VP 4 is obstructed. From VP 5, two different horizontal velocities are identified inside the platform; $v_{a}<v_{b}$.

\section{DISCUSSION}

The Darcy-Weisbach equations can be used to identify primary and secondary energy losses in a flow system similar to the one shown here. However, the use of the VOF method allows visualizing the distribution of the resulting velocity vectors and in particular the effect of the atmospheric pressure on the flow velocity inside the tunnel. The natural operating conditions of the ventilation system have been altered by placing a deflector at the fan outlet. The deflector has increased the effect (positive or negative) of the atmospheric pressure on the ventilation system and has shown that in the case of air injection this effect is enhanced. In the case of injection, the deflector has generated a considerable loss of pressure required to 
maintain adequate ventilation conditions. This effect has a direct consequence on the velocity of air inside the passenger platform. There is a situation of abrupt velocity change whose boundary is defined by VP 3 and VP 4 and this effect must be considered for the case of smoke or any other transport of pollutants coming from the tunnel.
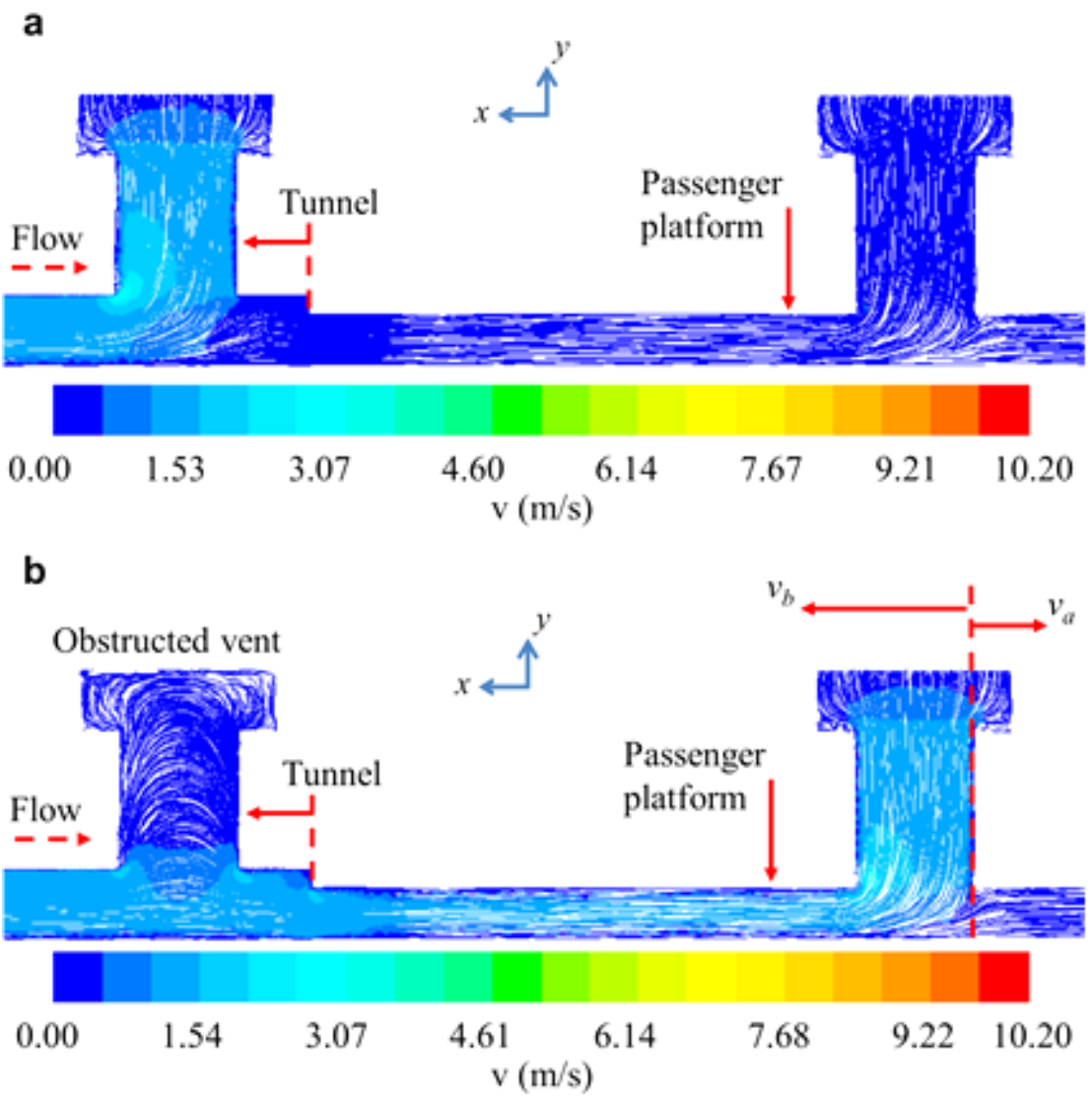

Figure 12: Path lines of the velocity distribution a) for case 3 and b) for case 5.

\section{CONCLUSION}

In this paper the critical velocity of an actual subway tunnel section of the Mexico City with $1400 \mathrm{~m}$ in length was analysed using Computer Fluid Dynamics (CFD) with ANSYS ${ }^{\circledR}$ Fluent and NFPA calculation. It was analysed the case where two natural ventilation ports were totally blocked, obtaining in this situation a maximum of $\pm 0.1 \mathrm{~m} / \mathrm{s}$ in difference with respect to the unblocked vents. Nevertheless it is identified that the architectural conditions significantly affect the distribution of air in the tunnel, producing a velocity difference close to $1.5 \mathrm{~m} / \mathrm{s}$ inside the passenger platform. This condition has to be considered in the case of smoke transportation or during the extraction of any other contaminant flowing in the tunnel.

The proposal to include a fan deflector to improve the distribution of the flow through the tunnel demonstrated to be not enough to reach the required critical velocity in the injection mode. The effect of the atmospheric pressure was enhanced with the inclusion of this deflector and allows observing that the atmospheric pressure contributes to the circulation of the air inside the tunnel when the fans are working in the extraction mode. The establishment of experimental measurements and real emergency simulations requires strong coordination and investment in training, human resources, specialized equipment, experiment scheduling, logistics and improved communication channels between internal and external departments to increase the understanding of the physical phenomena in subterranean installations for all the people involved on passenger security. 


\section{ACKNOWLEDGEMENTS}

Authors acknowledge the Consejo Nacional de Ciencia y Tecnología (CONACYT), the Instituto Politécnico Nacional (IPN) and the Metropolitan Public Transport System of Mexico City (CDMX), for their contribution to the development of this academic research.

\section{REFERENCES}

[1] Roh, J. S.; Ryou, H. S.; Park, W. H.; Jang, Y. J. (2009). CFD simulation and assessment of life safety in a subway train fire, Tunnelling and Underground Space Technology, Vol. 24, No. 4, 447-453, doi:10.1016/j.tust.2008.12.003

[2] Leitner, A. (2001). The fire catastrophe in the Tauern tunnel: experience and conclusions for the Austrian guidelines, Tunnelling and Underground Space Technology, Vol. 16, No. 3, 217-223, doi:10.1016/S0886-7798(01)00042-6

[3] Black, W. Z. (2009). Smoke movement in elevator shafts during a high-rise structural fire, Fire Safety Journal, Vol. 44, No. 2, 168-182, doi:10.1016/j.firesaf.2008.05.004

[4] Pflitsch, A.; Bruene, M.; Steiling, B.; Killing-Heinze, M.; Agnew, B.; Irving, M.; Lockhart, J. (2012). Air flow measurements in the underground section of a UK light rail system, Applied Thermal Engineering, Vol. 32, 22-30, doi:10.1016/j.applthermaleng.2011.07.030

[5] Hinkley, P. L. (1970). The flow of hot gases along an enclosed shopping mall: a tentative theory, Fire Research Notes, No. 807, 1-30

[6] Juraeva, M.; Ryu, K. J.; Jeong, S.-H.; Song, D. J. (2013). Influence of mechanical ventilationshaft connecting location on subway tunnel ventilation performance, Journal of Wind Engineering and Industrial Aerodynamics, Vol. 119, 114-120, doi:10.1016/j.jweia.2013.05.016

[7] Grant, G. B.; Jagger, S. F.; Lea, C. J. (1998). Fires in tunnels, Philosophical Transactions of the Royal Society of London, Series A: Mathematical, Physical and Engineering Sciences, Vol. 356, No. 1748, 2873-2906, doi:10.1098/rsta.1998.0302

[8] Weng, M.-C.; Lu, X.-L.; Liu, F.; Shi, X.-P.; Yu, L.-X. (2015). Prediction of backlayering length and critical velocity in metro tunnel fires, Tunnelling and Underground Space Technology, Vol. 47, 64-72, doi:10.1016/j.tust.2014.12.010

[9] Oka, Y.; Atkinson, G. T. (1995). Control of smoke flow in tunnel fires, Fire Safety Journal, Vol. 25, No. 4, 305-322, doi:10.1016/0379-7112(96)00007-0

[10] Hu, L. H.; Huo, R.; Wang, H. B.; Yang, R. X. (2007). Experimental and numerical studies on longitudinal smoke temperature distribution upstream and downstream from the fire in a road tunnel, Journal of Fire Sciences, Vol. 25, No. 1, 23-43, doi:10.1177/0734904107062357

[11] Rie, D.-H.; Hwang, M.-W.; Kim, S.-J.; Yoon, S.-W.; Ko, J.-W.; Kim, H.-Y. (2006). A study of optimal vent mode for the smoke control of subway station fire, Tunnelling and Underground Space Technology, Vol. 21, No. 3-4, 300-301, doi:10.1016/j.tust.2005.12.157

[12] Gutierrez-Montes, C.; Sanmiguel-Rojas, E.; Viedma, A.; Rein, G. (2009). Experimental data and numerical modelling of 1.3 and $2.3 \mathrm{MW}$ fires in a $20 \mathrm{~m}$ cubic atrium, Building and Environment, Vol. 44, No. 9, 1827-1839, doi:10.1016/j.buildenv.2008.12.010

[13] National Fire Protection Association (2003). NFPA 130 Standard for Fixed Guideway Transit and Passenger Rail Systems, NFPA Publications, Quincy

[14] Ko, Y. J.; Hadjisophocleous, G. V. (2013). Study of smoke backlayering during suppression in tunnels, Fire Safety Journal, Vol. 58, 240-247, doi:10.1016/j.firesaf.2013.03.001

[15] Yi, L.; Xu, Q.; Xu, Z.; Wu, D. (2014). An experimental study on critical velocity in sloping tunnel with longitudinal ventilation under fire, Tunnelling and Underground Space Technology, Vol. 43, 198-203, doi:10.1016/j.tust.2014.05.017

[16] Gannouni, S.; Maad, R. B. (2015). Numerical study of the effect of blockage on critical velocity and backlayering length in longitudinally ventilated tunnel fires, Tunnelling and Underground Space Technology, Vol. 48, 147-155, doi:10.1016/j.tust.2015.03.003

[17] Zhang, S.; Cheng, X.; Yao, Y.; Zhu, K.; Li, K.; Lu, S.; Zhang, R.; Zhang, H. (2016). An experimental investigation on blockage effect of metro train on the smoke back-layering in subway tunnel fires, Applied Thermal Engineering, Vol. 99, 214-223, doi:10.1016/ j.applthermaleng.2015.12.085 
[18] Zhang, S.; Yao, Y.; Zhu, K.; Li, K.; Zhang, R.; Lu, S.; Cheng, X. (2016). Prediction of smoke back-layering length under different longitudinal ventilations in the subway tunnel with metro train, Tunnelling and Underground Space Technology, Vol. 53, 13-21, doi:10.1016/ j.tust.2015.12.013

[19] Zvar Baskovic, U.; Lorenz, M.; Butala, V. (2014). Adiabatic flow simulation in air-conditioned vehicle passenger compartment, International Journal of Simulation Modelling, Vol. 13, No. 1, 42-53, doi:10.2507/IJSIMM13(1)4.253

[20] Gao, R.; Li, A.; Zhang, Y.; Luo, N. (2015). How domes improve fire safety in subway stations, Safety Science, Vol. 80, 94-104, doi:10.1016/j.ssci.2015.07.015

[21] Huang, Y.-D.; Gong, X.-L.; Peng, Y.-J.; Lin, X.-Y.; Kim, C.-N. (2011). Effects of the ventilation duct arrangement and duct geometry on ventilation performance in a subway tunnel, Tunnelling and Underground Space Technology, Vol. 26, No. 6, 725-733, doi:10.1016/j.tust.2011.05.005

[22] Zhong, W.; Fan, C. G.; Ji, J.; Yang, J. P. (2013). Influence of longitudinal wind on natural ventilation with vertical shaft in a road tunnel fire, International Journal of Heat and Mass Transfer, Vol. 57, No. 2, 671-678, doi:10.1016/j.ijheatmasstransfer.2012.10.063

[23] Simcox, S.; Wilkes, N. S.; Jones, I. P. (1992). Computer simulation of the flows of hot gases from the fire at King's Cross underground station, Fire Safety Journal, Vol. 18, No. 1, 49-73, doi: $10.1016 / 0379-7112(92) 90047-\mathrm{G}$

[24] Cheng, L. H.; Ueng, T. H.; Liu, C. W. (2001). Simulation of ventilation and fire in the underground facilities, Fire Safety Journal, Vol. 36, No. 6, 597-619, doi:10.1016/S03797112(01)00013-3

[25] Huang, Y.-D.; Gong, X.-L.; Peng, Y.-J.; Kim, C.-N. (2013). Effects of the solid curtains on natural ventilation performance in a subway tunnel, Tunnelling and Underground Space Technology, Vol. 38, 526-533, doi:10.1016/j.tust.2013.08.009

[26] Li, Q.; Deng, Y.; Liu, C.; Zeng, Q.; Lu, Y. (2016). Modeling and analysis of subway fire emergency response: an empirical study, Safety Science, Vol. 84, 171-180, doi: $\underline{10.1016 /}$ j.ssci.2015.12.003

[27] ANSYS, Inc. (2013). ANSYS FLUENT Theory Guide V. 15, Canonsburg

[28] Chorin, A. J. (1968). Numerical solution of the Navier-Stokes equations, Mathematics of Computation, Vol. 22, No. 104, 745-762, doi:10.1090/S0025-5718-1968-0242392-2

[29] Batchelor, G. K. (1967). An introduction to fluid dynamics, Cambridge University Press, Cambridge 